\title{
Mitogenic Activity of Neu Differentiation Factor/Heregulin Mimics That of Epidermal Growth Factor and Insulin-Like Growth Factor-I in Human Mammary Epithelial Cells
}

\author{
TRACY G. RAM, KRISTINE E. KOKENY, CHERYL A. DILTS, AND STEPHEN P. ETHIER* \\ Department of Radiation Oncology, Division of Radiation and Cancer Biology, The \\ University of Michigan Medical School, Ann Arbor, Michigan 48109-0582
}

\begin{abstract}
Recently, a family of growth factors has been described that activates erbB-2 receptors. These factors, known as the neu differentiation factors (NDF) or heregulins (HRG), induce tyrosine phosphorylation of erbB-2 receptors as a result of their direct interaction with either erbB-3 or erbB-4 receptors. Although it is known that expression of erbB-2 receptors has relevance in human breast cancer progression, how erbB-2, -3 and -4 receptors regulate mammary epithelial cell proliferation is not known. Therefore, experiments were carried out to study the mitogenic activity of NDF/HRG on the human mammary epithelial cell line MCF$10 \mathrm{~A}$ which can be cultured continuously under serum-free conditions. MCF-10A cells, like primary cultures of normal human mammary epithelial cells, express an absolute requirement for exogenous epidermal growth factor (EGF) and insulinlike growth factor I (IGF-I) for growth. The results of these experiments indicate that NDF/HRG can induce tyrosine phosphorylation of p185erbB-2 in MCF-10A cells and is mitogenic for these cells. This is consistent with the coexpression of erbB-2 and erbB-3 mRNA that we have observed in MCF-10A cells. In addition, we found that NDF/HRG can substitute for either EGF or IGF-I to stimulate proliferation of these cells. The ability to substitute for both EGF and IGF-I is a unique property of NDF/HRG and is not shared by other members of the EGF or IGF family of growth factors, nor by other factors that we have studied. A striking isoform specificity was also observed which indicated that the $\beta$-isoforms of NDF/HRG were greater than ten times more mitogenic than the $\alpha$-isoforms. We also examined the mitogenic activity of NDF/HRG on MCF-10A cells that overexpress the erbB-2 receptor as a result of infection with a retroviral vector containing the human c-erbB-2 gene (MCF-10AerbB-2 cells). These studies indicated that MCF-10AerbB-2 cells have increased sensitivity to the mitogenic effects of NDF/ HRG and that these cells are responsive to the $\alpha$-isoforms of NDF/HRG at physiological concentrations. Thus, NDF/HRG is a dual specificity growth factor for human mammary epithelial cells, and the responsiveness of the cells to NDF/HRG is influenced by the level of expression of erbB-2 receptors.

(c) 1995 Wiley-Liss, Inc.
\end{abstract}

Normal human mammary epithelial cells proliferate in culture under defined serum-free conditions in response to growth factors that activate distinct signal transduction pathways (Stampfer et al., 1980; Hammond et al., 1984; Ethier et al., 1987, 1990). These cells require stimulation of the insulin-like growth factor (IGF)-I, receptor by either IGF-I, IGF-II, or supraphysiological concentrations of insulin (IN), and stimulation of the EGF receptor by either epidermal growth factor (EGF) or TGF- $\alpha$. The presence of saturating concentrations of EGF does not induce cell growth in the absence of IGF-I and vice versa. Thus, these pathways interact synergistically to drive proliferation of human mammary epithelial cells.

Recently, a family of growth factors that activates the erbB-2 receptors has been described (Holmes et al., 1992; Wen et al., 1992). These factors, termed the neu differentiation factors (NDF) or heregulins (HRG), bind directly to erbB-3 and erbB-4 receptors and can bind to heterodimers of erbB-2 and erbB-3, resulting in activation of erbB-2 proteins (Plowman et al., 1993b; Kraus et al., 1993; Carraway et al., 1994; Sliwkowski et al., 1994). Given that erbB-2, erbB-3, and erbB-4 are members of the EGF receptor family of proteins, one might predict that NDF/HRGs would have mitogenic activity similar to that of EGF. Therefore, we examined the ability of pure human recombinant NDF/HRG to sub-

Received July 25, 1994; accepted November 2, 1994.

*To whom reprint requests/correspondence should be addressed at the Department of Radiation Oncology, University of Michigan Medical School, 1331 East Ann Street, Ann Arbor, MI 481090582 . 
stitute for EGF to induce proliferation of the human mammary epithelial cell line MCF-10A. MCF-10A cells, like primary cultures of normal human mammary epithelial cells, have a strict requirement for EGF and IGF-I for growth in serum-free culture (Ethier and Moorthy, 1991; Ethier et al., 1991). Not surprisingly, NDF/HRG was found to have mitogenic activity toward MCF-10A cells when cultured in EGF-free medium. However, we also found that NDF/HRG can induce proliferation of MCF-10A cells in EGF-containing medium that is devoid of insulin or IGF-I. Thus, our results indicate that NDF/HRG is a dual specificity growth factor that can substitute for both EGF and IGF-I to stimulate growth of human mammary epithelial cells. This property of NDF/HRG is, as far as we know, unique and is not shared by a number of other growth factors that we have studied, including transforming growth factor- $\alpha$ (TGF- $\alpha$ ), IGF-I, IGF-II, acidic fibroblast growth factor (FGF), bFGF, plate derived growth factor (PDGF), keratinocyte growth factor (KGF), or hepatocyte growth factor (HGF). This pleiotropic growth factor activity of NDF/HRG in mammary epithelial cells may explain the selective growth advantage that is acquired by human breast cancer cells as a result of amplification and/or overexpression of the c-erbB-2 gene.

\section{MATERIALS AND METHODS Cell culture conditions and assays for mitogenic activity}

MCF-10A cells are a human mammary epithelial cell line that was isolated from nonmalignant breast tissue (Soule et al., 1990). In our laboratory, MCF-10A cells are routinely cultured on type-I collagen-coated tissue culture dishes in serum-free Ham's F-12 medium supplemented with bovine serum albumin, transferrin, ethanolamine, sodium selenite, triiodothyronine, insulin, hydrocortisone, and epidermal growth factor (Ethier and Moorthy, 1991; Ethier et al., 1991). To test for EGF-like or IGF-like activity of NDF/HRG, MCF-10A cells were seeded in $35 \mathrm{~mm}$ collagen-coated wells at $3.5 \times 10^{4}$ cells per well in Ham's F-12 medium devoid of either insulin or EGF and containing $2 \%$ serum to allow attachment. The next day, this plating medium was removed, and the cells were switched to the serum-free Ham's F-12 medium described above but without either insulin or EGF and containing one of the NDF/HRG isoforms. The cells were grown for 7 days with two media changes, and the number of cells per dish was determined by counting isolated nuclei with a Coulter Counter as described previously (Ethier et al., 1987). Human recombinant NDF/HRG used in these studies was kindly provided by Dr. Barry Ratzkin (Amgen Inc, Thousand Oaks, CA). The various isoforms of NDF/ HRG were made in $\mathrm{E}$. Coli and purified by reverse phase HPLC, and the purity was confirmed by N-terminal sequence analysis and gel electrophoresis. The sequences of the various NDF/HRG isoforms has been published previously (Holmes et al., 1992). All of the isoforms were demonstrated to induce erbB-2 phosphorylation in MDA-MB-453 cells. MCF-10-erbB-2 cells were kindly provided by Dr. David Salomon of the National Cancer Institute (Bethesda, MD). These cells were derived by infection of MCF-10A cells with an amphotropic retroviral expession vector containing the full-length human erbB-2 cDNA (Ciardiello et al., 1992).

\section{Immunoprecipitation and Western blot analysis}

For preparation of membranes to be used in Western blot experiments, confluent monolayers of cells were scraped in $20 \mathrm{mM}$ HEPES containing $20 \mathrm{mM}$ sodium orthovanadate, $10 \mathrm{mM}$ sodium pyrophosphate, and 1 $\mathrm{mM}$ phenylmethyl sulfonyl fluoride, dounced homogenized 50 times, and centrifuged at $800 \mathrm{~g}$ for $10 \mathrm{~min}$. The supernatant was then centrifuged at $100,000 \mathrm{~g}$ for 30 min and the pellet resuspended in a lysis buffer consisting of $10 \mathrm{mM}$ phosphate ( $\mathrm{pH} 7.5), 100 \mathrm{mM} \mathrm{NaCl}, 1 \%$ Triton X-100, $0.5 \%$ sodium deoxycholate, $0.1 \%$ SDS, 5 $\mathrm{mM}$ sodium orthovanadate, and $10 \mathrm{mM}$ sodium pyrophosphate. The lysate was assayed for protein content, and then defined amounts of membrane protein were added to individual wells, electrophoresed, and blotted onto Imobilon-P membranes, blocked with $3 \%$ nonfat dry milk in Tris-buffered saline with $0.1 \%$ Tween-20; then blots were probed either with erbB-2 antibodies (Pab 9.3, kindly provided by Dr. Beatrice Langton, Berlex Biosciences, Richmond, CA) or anti-phosphotyrosine antibodies (PY-20, ICN, Costa Mesa, CA). Protein bands were visualized by incubating blots in biotinylated anti-rabbit (for Pab 9.3) or anti-mouse (for PY-20) IgG and then with Vectastain ABC reagents (Vector Laboratories, Burlingame, CA) using diaminobenzidine as a substrate. Alternatively, bands were visualized by Enhanced Chemoluminescence (Amersham, Arlington Heights, IL) following incubation in Vectastain ABC.

For immunoprecipitation experiments, ten confluent $60 \mathrm{~mm}$ dishes per group of MCF-10A cells were lysed in

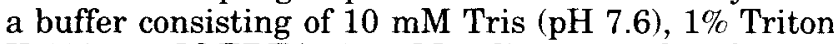
$\mathrm{X}-100,5 \mathrm{mM}$ EDTA, $10 \mathrm{mM}$ sodium pyrophosphate, 5 $\mathrm{mM}$ sodium fluoride, $5 \mu \mathrm{M}$ sodium orthovanadate, $0.1 \%$ sodium azide, and $1 \mathrm{mM}$ phenylmethyl sulfonyl fluoride. All ten plates were lysed in $200 \mu$ l lysis buffer by sequential addition of buffer from one plate to the next. Cells were scraped into the lysis buffer with a rubber policeman. The lysate was incubated on ice for $15 \mathrm{~min}$ and then centrifuged at $14,000 \mathrm{~g}$ for $15 \mathrm{~min}$. Next, $100 \mu \mathrm{l}$ of lysate was incubated with $100 \mu \mathrm{l}$ of anti-phosphotyrosine-agarose (Oncogene Science, Union dale, $N Y$ ) for $2 \mathrm{~h}$ at room temperature with agitation. The beads were washed three times by centrifugation at 2,000g for $1 \mathrm{~min}$. Proteins were eluted from the beads by addition of lysis buffer containing $50 \mathrm{mM}$ phenyl phosphate and incubating at room temperature for $2 \mathrm{~h}$. The beads were then centrifuged, and the eluate was mixed with SDS-sample buffer, boiled for $5 \mathrm{~min}$, and loaded onto a 7\% SDS-polyacrylamide gel and electrophoresed. Following electrophoresis, the proteins were electroblotted and analyzed as described above.

\section{RT-PCR for erbB-3 and erbB-4}

Oligonucleotide primers for RT-PCR were constructed using published sequences of erbB-3 and erbB-4 mRNA (Kraus et al., 1989; Plowman et al., $1990,1993 \mathrm{a})$. For reverse transcription of erbB-3 mRNA, a 20-mer primer (5'-TCCGGGTGGCAGTGAGAAGCA-3') was synthesized complementary to 


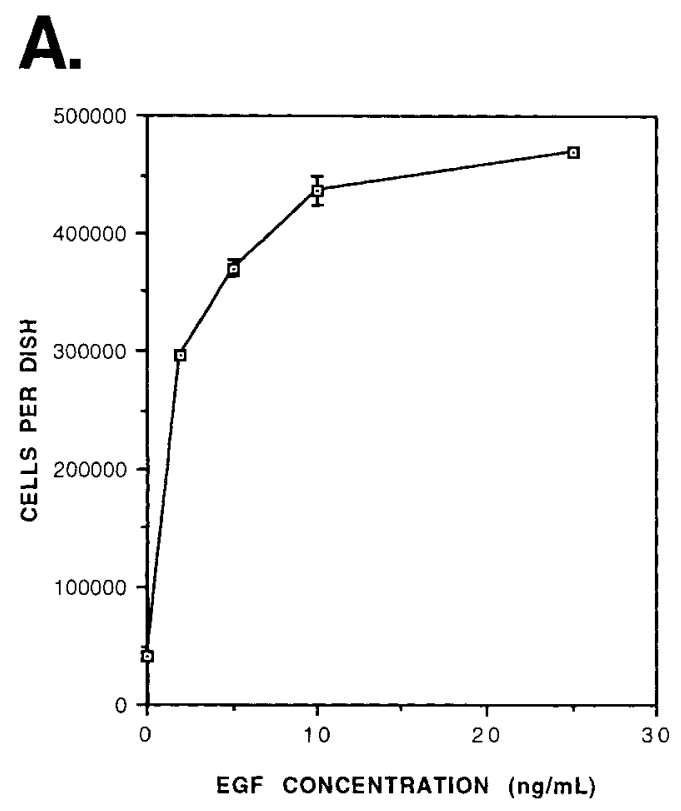

Fig. 1. Responsiveness of MCF-10A cells to varying concentrations of EGF (A) when cultured in serum-free medium containing saturating concentrations of IGF-I $(25 \mathrm{ng} / \mathrm{ml})$ or to varying concentrations of IGF-I (B) when cultured in the presence of saturating concentrations of EGF (10 ng/ml). MCF-10A cells were seeded at $3.5 \times 10^{4}$ cells per 35 $\mathrm{mm}$ well and cultured for 7 days in serum-free medium containing the

positions 1744 to 1763 or erbB-3 mRNA. For PCR amplification of erbB-3, a 22-mer upstream primer (5'GACCGGCGATGCTGAGAACCAA-3') was synthesized identical to positions 213 to 234 of erbB-3 mRNA and a 24-mer downstream primer (5'-GGGCCCAAAGCAGTGACCATTACA-3') was synthesized complementary to positions 739 to 762 . The expected size of the erbB-3 PCR product is 550 base pairs. For reverse transcription of erbB-4 mRNA, a 20-mer primer (5'-TCACACTGGGGGTCACACTC-3') complementary to positions 1693 to 1712 was utilized. PCR amplification of erbB-4 mRNA was performed using a 21-mer upstream primer identical to positions 252 to 272 of erbB-4 mRNA and a 24-mer downstream primer (5'-AAGTCTGGCAATGATTTTCTGTGG-3') complementary to positions 632 to 655 . The expected size of the erbB-4 PCR product is 404 base pairs.

RNA from cells in one confluent $60 \mathrm{~mm}$ tissue culture dish was isolated using the RNAzol B method (TelTest, Inc., Friendswood, TX). The final RNA pellet was washed with $75 \%$ ethanol, dried, and resuspended in 20 $\mu l$ DEPC-treated water. Ten microliters of this RNA preparation was used in the reverse transcription reaction in combination with $10 \mu l 5 \times$ reverse transcription buffer (Boehringer Mannheim, Indianapolis, IN), $1 \mu l$ $25 \mathrm{mM}$ dXTP solution, $2 \mu \mathrm{g}$ reverse transcription primer, DEPC water to $50 \mu l$, and $1 \mu$ l reverse transcriptase (Boehringer Mannheim). This mixture was incubated at $41^{\circ} \mathrm{C}$ for $1 \mathrm{~h}$. The reverse transcriptase was then deactivated by heating the samples at $95^{\circ} \mathrm{C}$ for $2-3$ min. Ten microliters of the resulting cDNA was added to PCR tubes containing $5 \mu \mathrm{l}$ of $10 \mathrm{X}$ adjust buffer (400 mM KCl, $0.1 \%$ gelatin), $5 \mu \mathrm{l} 1 \mathrm{mM}$ dXTP

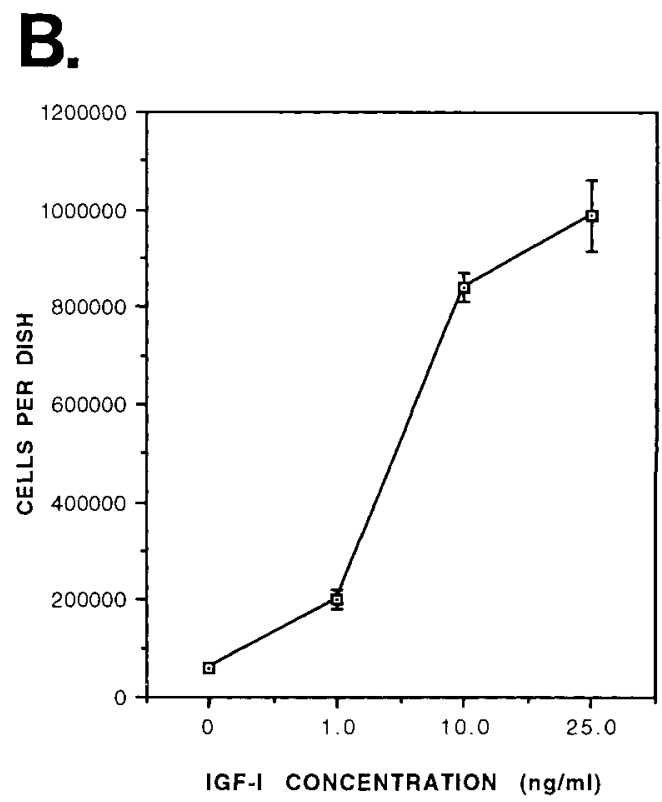

indicated concentration of growth factor. The number of cells per dish was determined at the end of the experiment by counting isolated nuclei with a Coulter Counter. The results represent the mean number of cells per well for triplicate wells and the error bars indicate the range.

solution, 1 unit Taq polymerase (Boerhinger Mannheim $\mathrm{GmbH}$ ), and DEPC-treated water to $50 \mu \mathrm{l}$. Thermocycling was performed for 30 cycles at $94^{\circ} \mathrm{C}$ for 1 $\min , 55^{\circ} \mathrm{C}$ for $1 \mathrm{~min}$, and $72^{\circ} \mathrm{C}$ for $3 \mathrm{~min}$. After thermocycling, each PCR sample was electrophoresed through a $3 \%$ Nusieve, $1 \%$ agarose minigel stained with ethidium bromide.

\section{RESULTS}

IGF-I and EGF requirements of MCF-10A cells

The human mammary epithelial cell line, MCF-10A, expresses strict requirements for exogenous EGF and IGF-I (or supraphysiological concentrations of insulin) for growth in serum-free medium (Ethier and Moorthy, 1991; Ethier et al., 1991). The data in Figure 1A,B show the responsiveness of these cells to varying concentrations of each factor when added to culture medium containing saturating concentrations (10 ng/ml EGF, 25 $\mathrm{ng} / \mathrm{ml}$ IGF-I) of the complementing growth factor. Thus, EGF was present when IGF-I concentrations were varied and vice versa. These results indicate that proliferation of MCF-10A cells does not take place unless both factors are present. Furthermore, EGF-like factors such as TGF- $\alpha$ cannot substitute for IGF-I, and IGFlike factors such as insulin and IGF-II cannot substitute for EGF (unpublished observations). Thus, in MCF-10A cells, like in primary cultures of human (Ethier et al., 1990) and rat mammary epithelial cells (Ethier et al., 1987), EGF and IGF-I interact synergistically to stimulate cell proliferation. 


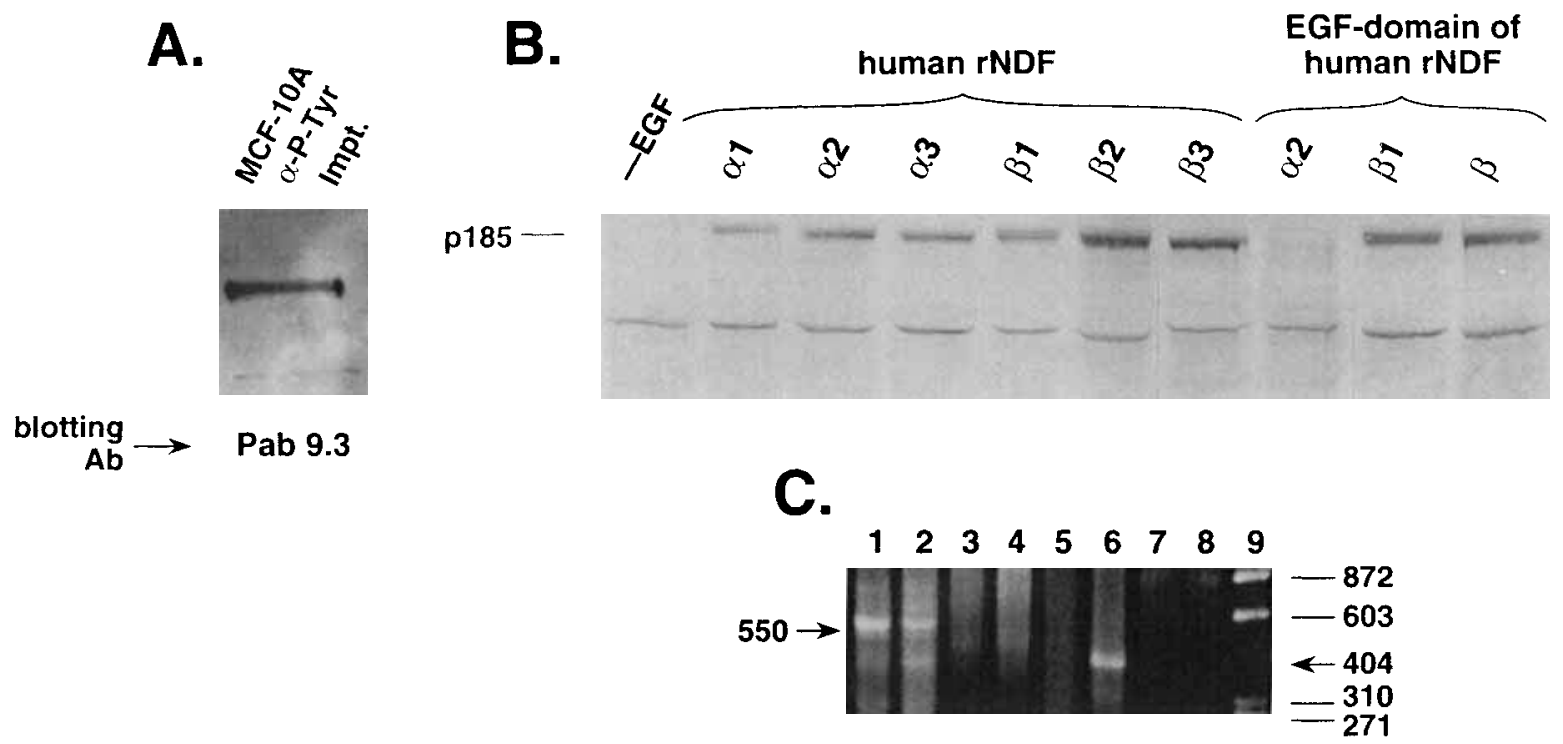

Fig. 2. Tyrosine phosphorylation of erbB-2 receptors in MCF-10A cells exposed to various $\mathrm{NDF} / \mathrm{HRG}$ isoforms. A: MCF-10A cells were incubated in EGF-free medium overnight and exposed to $10 \mathrm{ng} / \mathrm{ml}$ of $\beta 2-N D F / H R G$ for $1 \mathrm{~h}$. Cell lysates were immunoprecipitated using a phosphotyrosine antibody conjugated to agarose beads. The immunoprecipitate was electrophoresed and blotted, and the Western blot was probed with the erbB-2-specific antibody Pab 9.3. B: Phosphotyrosine Western blot analysis of membrane protein obtained from MCF-10A cells following exposure to one of the NDF/HRG isoforms. All cells were exposed to NDF/HRG for 1-h in EGF-free medium, and lane 1 represents the control cells that were not exposed to NDF/HRG. C: RT-PCR analysis of erbB-3 and erbB-4 expression in MCF-10A cells. Lane 1: MCF-10A cells with erbB-3 primers. Lane 2: SkBr-3 cells with erbB-3 primers. Lanes 3,4: The same as 1 and 2 but without the reverse transcription step. Lane 5: MCF-10A cells with erbB-4 prim ers. Lane 6: T47D cells with erbB-4 primers. Lanes 7,8: The same as 5 and 6 but without the reverse transcription step. Lane 9: Size markers ( $\phi \times 174$ RF DNA cut with HaeIII).

\section{NDF/HRG stimulation of erbB-2 in MCF-10A cells}

To determine if exogenous NDF/HRG could activate erbB-2 receptors in $\mathrm{MCF}-10 \mathrm{~A}$ cells, monolayers of cells were grown to confluence in complete medium and switched to EGF-free medium overnight. The next day the cells were exposed to various NDF/HRG isoforms at a concentration of $10 \mathrm{ng} / \mathrm{ml}$ for $1 \mathrm{~h}$. Phosphotyrosine Western blot analysis of membrane protein obtained from these cells shows clearly that NDF/HRG induces rapid tyrosine phosphorylation of a $185 \mathrm{kDa}$ protein (Fig. 2B), and immunoprecipitation using phosphotyrosine antibodies coupled to erb B-2 Western blot experiments showed that P-tyr-185 is the erbB-2 protein (Fig. 2A). The results of the Western blot experiments indicate that all of the alpha and beta isoforms of NDF/ HRG are capable of activating erbB-2 in these cells. Furthermore, the EGF domains of the $\beta$-isoforms were able to activate erbB-2 in these cells, whereas the EGF domain of the $\alpha 2$-isoform was not. Since it is now known that NDF/HRG does not activate erbB-2 directly, RT-PCR analysis was carried out to determine if MCF-10A cells express mRNA for either erbB-3 or erbB-4. RT-PCR analysis using erbB-3 primers yielded the predicted 550 base pair amplification product with both MCF-10A cell RNA and SKBR-3 cell RNA which was used as a positive control (Kraus et al., 1989). RTPCR analysis using erbB-4 primers yielded the predicted 404 base pair amplification product in positive control T47D cells (Plowman et al., 1993a), but no product was observed using MCF-10A cell RNA. In all cases, control RT-PCR experiments in which the re- verse transcription step was omitted yielded no amplified products. Thus, these results indicate that MCF$10 \mathrm{~A}$ cells express erbB-3 but not erbB-4 mRNA (Fig. 2C). The coexpression of erbB-2 and erbB-3 by MCF-10A cells is consistent with their responsiveness to exogenous NDF/HRG (Peles et al., 1993; Carraway et al., 1994; Sliwkowski et al., 1994).

\section{EGF-like mitogenic activity of NDF/HRG}

To determine if exogenous NDF/HRG could substitute for EGF in stimulating growth of MCF-10A cells, MCF-10A cells were seeded at low density and grown for 7 days in serum-free, EGF-free medium that was supplemented with various NDF/HRG isoforms at a concentration of $10 \mathrm{ng} / \mathrm{ml}$. The results of this experiment are shown in Figure $3 \mathrm{~A}$ and indicate that MCF$10 \mathrm{~A}$ cells do not grow in EGF-free medium and that EGF can be replaced by NDF/HRG. In addition, the $\beta$-isoforms are significantly more potent mitogens than are the $\alpha$-isoforms. As in the Western blot studies, the EGF domains of the $\beta$-isoforms were mitogenically active, whereas the EGF domain of the $\alpha 2$ isoform was not. To compare the relative potencies of the different isoforms, similar experiments were performed using higher concentrations of the $\alpha$-isoforms, and these results are shown in Figure 3B. In the MCF-10A cells, $\alpha 2-\mathrm{NDF} / \mathrm{HRG}$ is mitogenic but is less than one-tenth as potent as the $\beta 2$ isoform of NDF/HRG, as $50 \mathrm{ng} / \mathrm{ml}$ of $\alpha 2-\mathrm{NDF} / \mathrm{HRG}$ is less active than $5 \mathrm{ng} / \mathrm{ml}$ of the $\beta 2$ isoform. Thus, these results show that activation of erbB-2 receptors by $\mathrm{NDF} / \mathrm{HRG}$ results in proliferation of MCF-10A cells in the absence of EGF and that there 

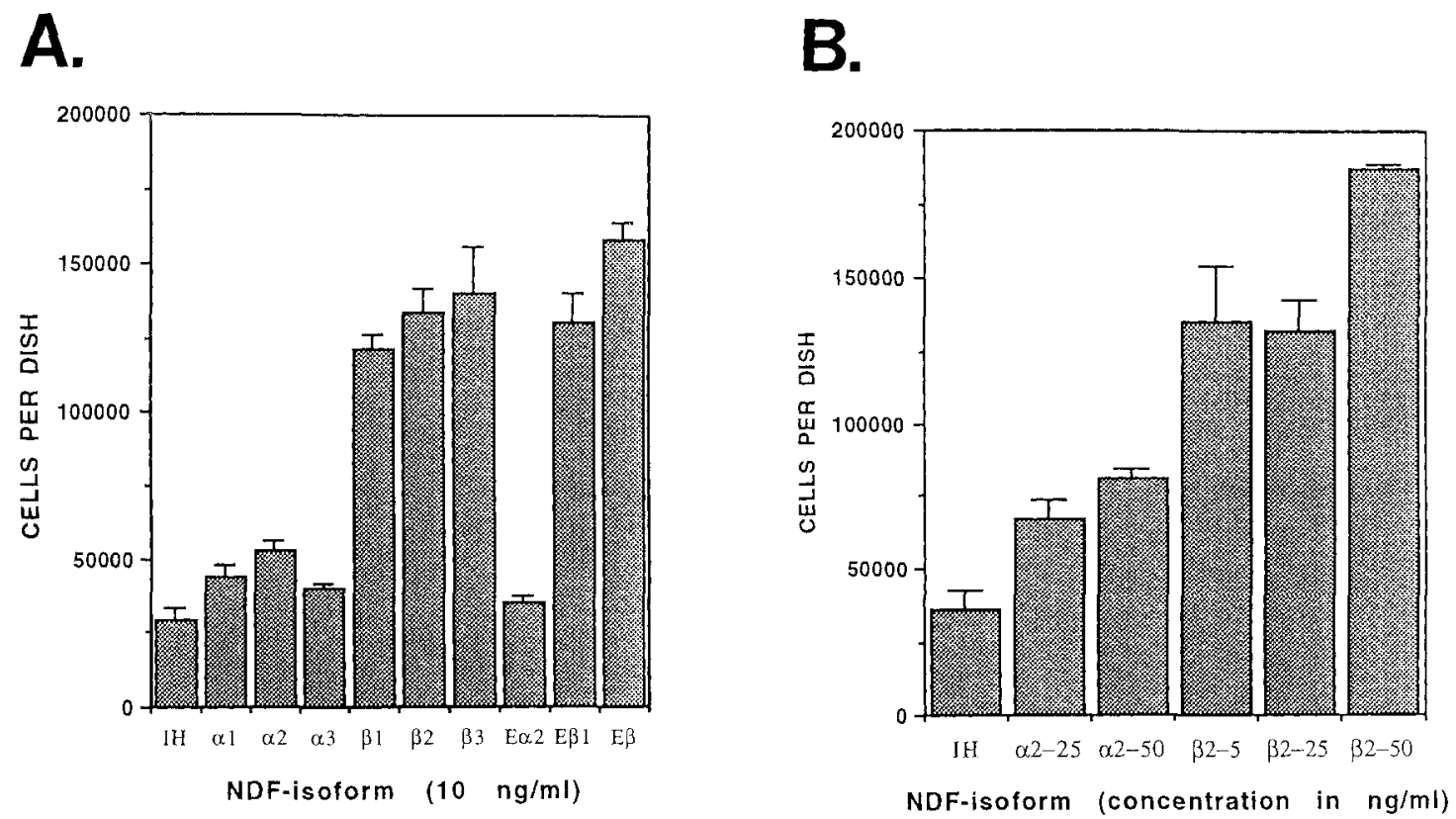

\begin{abstract}
Fig. 3. EGF-like mitogenic activity of NDF/HRG. IH indicates serum-free medium supplemented with insulin and hydrocortisone only. A: MCF-10A cells were cultured in serum-free, EGF-free medium in the presence of $10 \mathrm{ng} / \mathrm{ml}$ of one of the NDF/HRG isoforms. The cells were cultured for 7 days as described in Figure 1. B: MCF-10A cells were cultured in serum-free, EGF-free medium for 7 days in the presence of varying concentrations of either the $\alpha 2$ - or $\beta 2$-isoform of NDF/HRG.
\end{abstract}

is an isoform specificity for the mitogenic activity of this family of growth factors.

\section{IGF-like mitogenic activity of NDF/HRG}

Similar experiments were then performed to determine if NDF/HRG could stimulate growth of MCF-10A cells in medium supplemented with saturating concentrations of EGF in the absence of insulin or IGF-I. The results shown in Figure $4 \mathrm{~A}$ demonstrate that $32-\mathrm{NDF} /$ HRG can stimulate proliferation of MCF-10A cells in the absence of IGF-I and that maximal stimulation occurs at concentrations of approximately $10 \mathrm{ng} / \mathrm{ml}$. The data in Figure 4B show that the isoform specificity noted earlier for the EGF-like effects of NDF/HRG is also operative for its IGF-like activity in that the $\alpha$-isoforms have little mitogenic activity in IGF-free medium at this concentration. This result highlights the unique dual specificity of NDF/HRG in which it acts both as an IGF-like and EGF-like mitogen in stimulating the growth of MCF-10A cells.

\section{IGF-like activity of NDF/HRG in cells that overexpress erbB-2 receptors}

To determine if overexpression of the erbB-2 receptor would enhance the sensitivity of MCF-10A cells to the mitogenic effects of NDF/HRG, experiments were carried out with MCF-10A cells infected with a retroviral expression vector containing the full-length human c-erbB-2 gene (Ciardiello et al., 1992). These cells express elevated levels of erbB-2 relative to parental MCF-10A cells, and phosphotyrosine Western analysis indicated that erbB-2 is constitutively tyrosine phosphorylated in these cells (Fig. 5). To examine the mito- genic activity of NDF/HRG in MCF-10-erbB-2 cells, growth assays were performed as described above using serum-free, IGF-1-free medium. The data shown in Figure 6A indicates that MCF-10-erbB-2 cells are more responsive to lower concentrations of $32-\mathrm{NDF} / \mathrm{HRG}$, with maximum proliferation taking place at $1.0 \mathrm{ng} / \mathrm{ml}$ rather than $10 \mathrm{ng} / \mathrm{ml}$ required by the parental cells. The data shown in Figure $6 \mathrm{~B}$ indicates that MCF-10erbB-2 cells are also responsive to the $\alpha 2$-isoform of NDF/HRG. Whereas parental MCF-10A cells are essentially unresponsive to the $\alpha$-isoforms of $\mathrm{NDF} / \mathrm{HRG}$ under IGF-free conditions, MCF-10-erbB-2 cells are significantly growth stimulated by $\alpha 2-\mathrm{NDF} / \mathrm{HRG}$ at physiological concentrations. Thus, these data indicate that overexpression of erbB-2 by mammary epithelial cells confers enhanced sensitivity to the IGF-I-like mitogenic effects of all isoforms of $\mathrm{NDF} / \mathrm{HRG}$.

In summary, the results of these studies indicate that $\mathrm{NDF} / \mathrm{HRG}$ is a unique dual specificity growth factor that can stimulate mitogenic pathways normally activated separately by EGF and IGF-I. Furthermore, cells that express elevated levels of erbB-2 exhibit an enhanced sensitivity to this family of growth factors.

\section{DISCUSSION}

The results of the experiments presented here indicate that NDF/HRG can induce tyrosine phosphorylation of erbB-2 and stimulate proliferation of MCF-10A human mammary epithelial cells. The results also indicate that there is a dramatic isoform specificity with regard to the mitogenic activity of NDF/HRG on these cells. Interestingly, this specificity is not reflected in the ability of the various isoforms to induce tyrosine 
A.

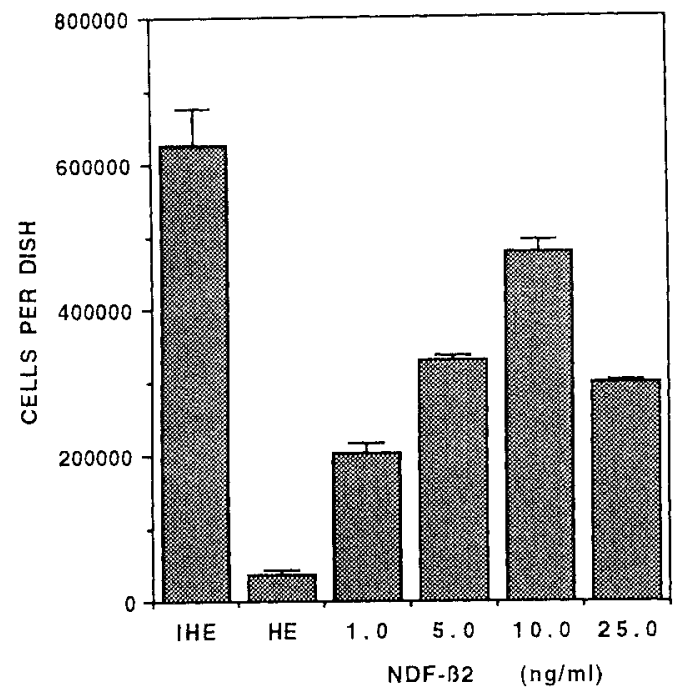

B.

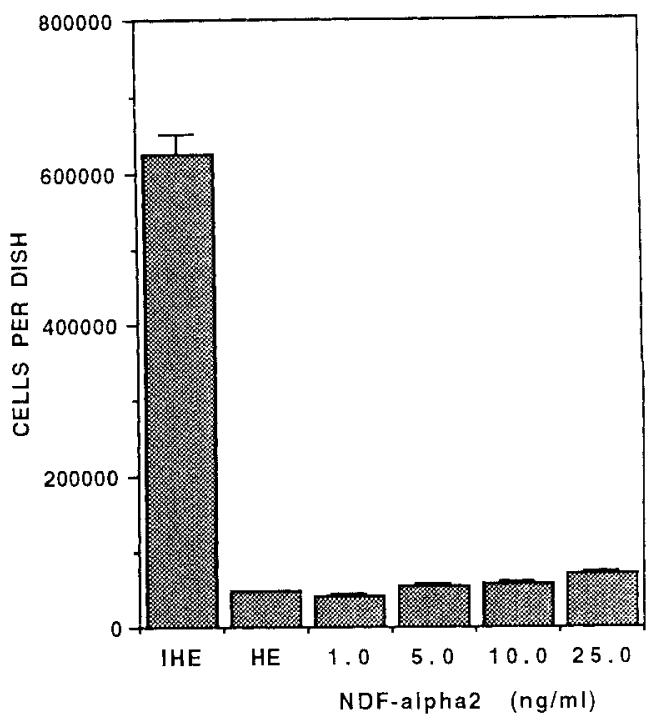

Fig 4. IGF-like mitogenic activity of NDF/HRG. MCF-10A cells were cultured in serum-free, IGF-free medium for 7 days in the presence of varying concentrations of the $\beta 2$-isoform (A) or the $\alpha 2$-isoform of NDF/HRG. (B) Growth assays were performed as described above. HE indicates serum-free medium supplemented with hydrocortisone and EGF only. IHE indicates medium supplemented with insulin, hydrocortisone and EGF.

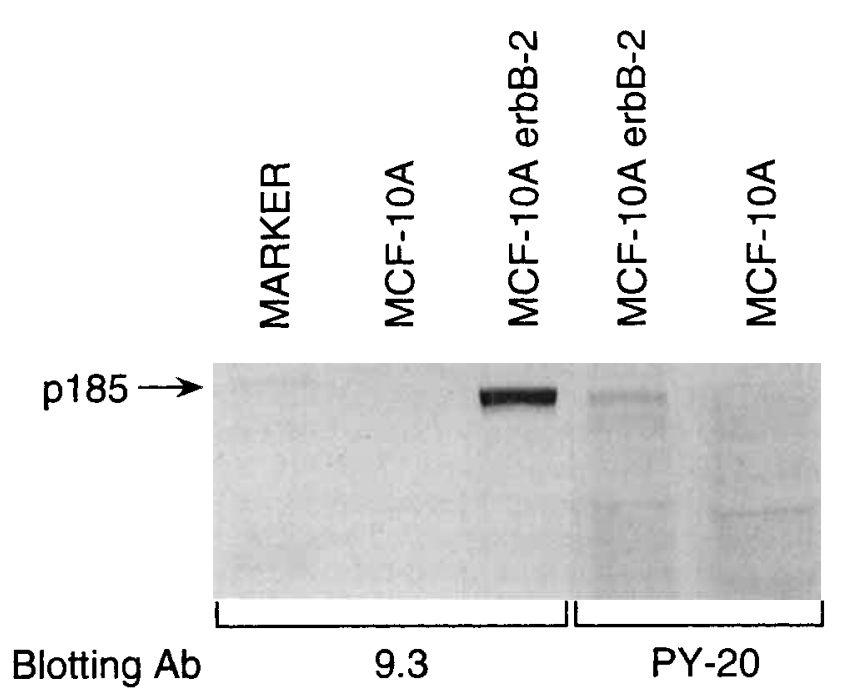

Fig. 5. Western blot analysis of erbB-2 expression and tyrosine phosphorylation in MCF-10A and MCF-10erbB-2 cells. Western blots were prepared from membrane protein obtained from MCF-10A or MCF-10erbB-2 cells and probed either with an erbB-2-specific antibody Pab 9.3 or with the anti-phosphotyrosine antibody PY -20 .

phosphorylation of erbB-2 receptors. Both the $\alpha$ - and $\beta$-isoforms of NDF/HRG have an EGF-like domain with conserved positioning of cystene residues. Yet there are sequence differences within the EGF domain that distinguish the two isoform types (Holmes et al., 1992). Since the EGF domain is known to be the receptor binding domain, these differences may influence the affinity of the various isoforms for the receptor, and the proliferation assay may be more sensitive to those differences than is the phosphotyrosine Western blot assay. The $\alpha$-isoforms of NDF/HRG are mitogenic toward MCF-10A cells, but ten- to twentyfold higher concentrations of this factor are required to stimulate growth to a level equivalent to that obtained with the $\beta$-isoforms. In addition, MCF-10A-erbB-2 cells, which overexpress erbB-2 receptors, exhibit increased responsiveness to NDF/HRG and respond to the $\alpha$-isoforms at physiological concentrations. These two observations are consistent with the hypothesis that affinity differences between the $\alpha$-and $\beta$-isoforms underlie the differences in their mitogenic potential.

The responsiveness of MCF-10A cells to NDF/HRG is indicative of the presence of functioning erbB-3 receptors in these cells. RT-PCR experiments clearly demonstrated the presence of erbB-3 mRN in MCF-10A cells. Given that NDF/HRG does not induce tyrosine phosphorylation in cells that express erbB-2 in the absence of either erbB-3 or erbB-4 (Carraway et al., 1994; Peles et al., 1993; Plowman et al., 1993b) and that our RTPCR experiments failed to detect erbB-4 mRNA in MCF-10A cells, we conclude that erbB-2/erbB-3 interactions take place in MCF-10A cells in response to $\mathrm{NDF} / \mathrm{HRG}$ and drive the biological responses observed in these experiments.

These studies also demonstrated that NDF/HRG is a dual specificity growth factor that can drive signal transduction pathways that normally require two distinct classes of growth factors. Thus, NDF/HRG can substitute for either EGF or IGF-I to stimulate growth of MCF-10A cells, and this is a unique property of this growth factor family. Results of recently published experiments may explain this interesting observation. As 

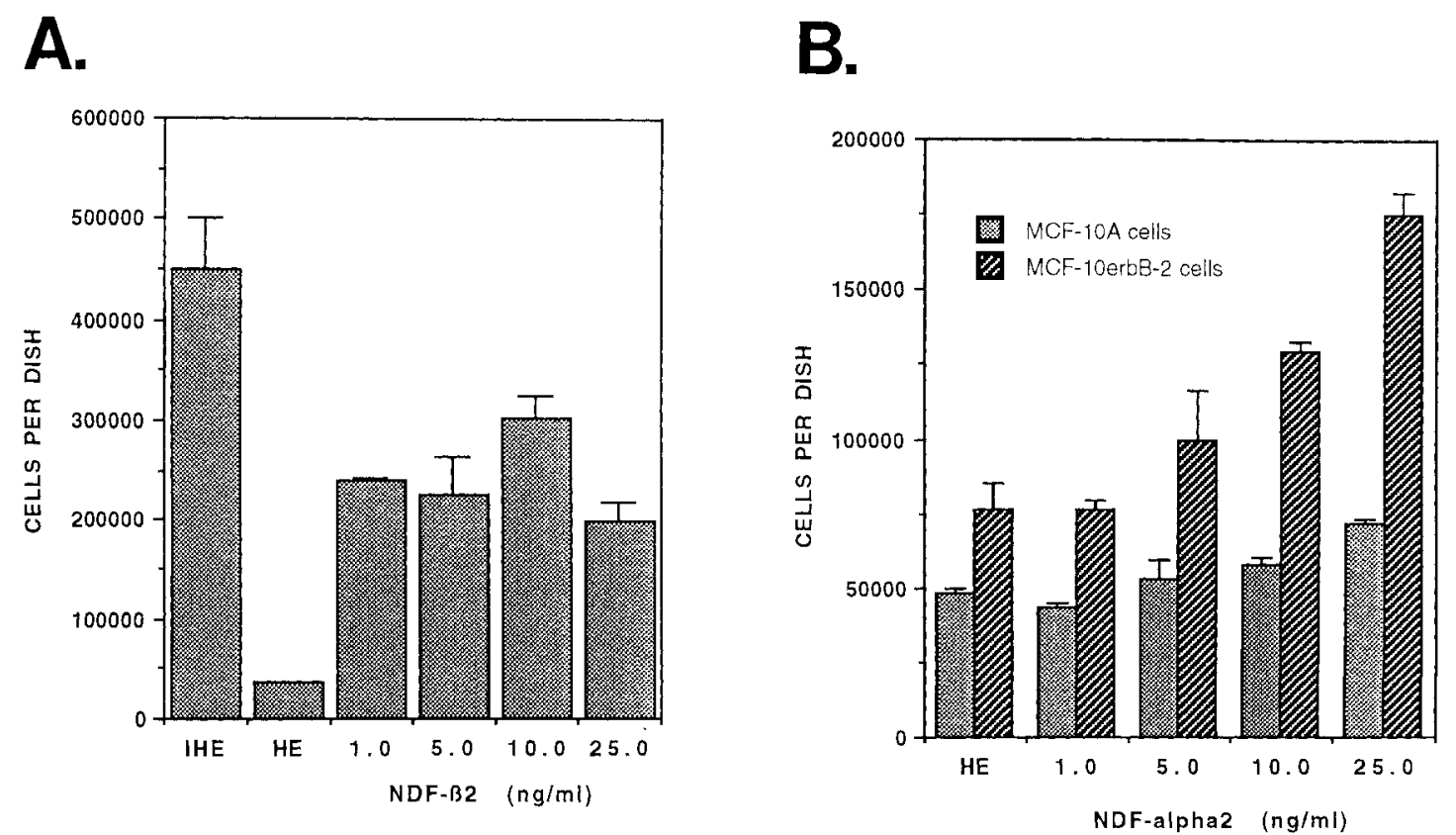

Fig. 6. IGF-like mitogenic activity of NDF/HRG on MCF-10-erbB-2 cells. MCF-10-erbB-2 cells were cultured in serum-free, IGF-free medium for 7 days in the presence of varying concentrations of $\beta 2-\mathrm{NDF} /$ HRG (A). B: The comparative response of MCF-10-erbB-2 cells and MCF-10A cells to varying concentrations of the $\alpha 2$-isoform of NDF/HRG when cultured under IGF-free conditions.

discussed above, erbB-2 receptors become activated in response to NDF/HRG when erbB-3 receptors are coexpressed. Indeed, erbB-2/erbB-3 heterodimers bind NDF/HRG with a higher affinity than do erbB-3 homodimers (Sliwkowski et al., 1994). This finding, coupled with results reported by Peles et al. (1991) and Fedi et al. (1994) suggest a mechanism for the dual activity of NDF/HRG observed in our experiments. Peles et al. (1991) demonstrated that activation of erbB-2 receptors results in association and activation of signaling molecules such as phospholipase C-gamma in a manner similar to that observed with activated EGF receptors. More recently, Fedi et al. (1994) demonstrated that activation of erbB-3 receptors results in association of phosphatidyl inositol 3-kinase (PI 3-kinase) with erbB-3 receptors with ten- to twentyfold greater efficiency than occurs following activation of EGF receptors. The ability to bind to and activate PI-3 kinase is a distinctive property of erbB-3 receptors that is not shared by either EGF receptors or erbB-2 receptors and is reflective of differences in the cytoplasmic domains between erbB-3 receptors and other members of the erbB family. Thus, erbB-3 receptors share signal transduction properties with molecules normally activated as a result of IGF-I-induced signaling. Activation of IGF-I receptors results in rapid phosphorylation of a substrate protein, IRS-1, which in turn binds to and activates (Backer et al., 1993). Thus, we propose that in cells that express erbB-2 receptors in conjunction with erbB-3 receptors and EGF receptors, stimulation by NDF/HRG results in activation of signal transduction pathways that are normally activated separately by EGF and IGF-I. This may occur by the formation of heterodimers among various erbB family members that yield both EGF-like signals and IGF-I-like signals.

We have found that the potency of NDF/HRG to act as an IGF-like mitogen is influenced by the level of erbB-2 expression. This observation has significance for human breast cancer in that a substantial fraction of human breast cancers overexpress erbB-2 receptors that are constitutively activated (Slamon et al., 1987; Ro et al., 1989; Zeillinger et al., 1989). Furthermore, it has been reported that $90 \%$ of human breast cancer cells express erbB-3 receptors (Kraus et al., 1989). Thus, the overexpression and activation of erbB-2 receptors in cells that coexpress erbB-3 receptors may result in breast cancer cells that are autonomous of both IGF-I-like and EGF-like mitogens for their proliferation.

\section{ACKNOWLEDGMENTS}

This work was supported by grant number CA40046 from the National Cancer Institute.

\section{LITERATURE CITED}

Backer, J.M., Myers, M.G., Sun, X.J., Chen, D.J., Shoelson, S.E., Mivalpeix, M., and White, M.F. (1993) Association of IRS-I with the insulin receptor and phosphadityl inositol-3 kinase. J. Biol. Chem., 268:8204-8212.

Carraway, K.L., Sliwkowski, M.X., Akita, R., Platko, J.V., Guy, P.M., Nuijens, A., Diamonti, A.J., Vandlen, R.L., Cantley, L.C., and Cerione, R.A. (1994) The erbB3 gene product is a receptor for heregulin. J. Biol, Chem., 269:14303-14306.

Ciardiello, F., Gottardis, M., Basolo, F., Pepe, S., Normanno, N., Dickson, R.B., Bianco, A.R., and Salomon, D.S. (1992) Additive effects of c-erbB-2, c-Ha-ras, and transforming growth factor-alpha genes on in vitro transformation of human mammary epithelial cells. Mol. Carcinogen., 6:43-52. 
Ethier, S.P., and Moorthy, R. (1991) Multiple growth factor independence in rat mammary carcinoma cells. Breast Cancer Res. Treat., 18:73-81.

Ethier, S.P., Kudla, A., and Cundiff, K.C. (1987) The influence of hormone and growth factor interactions on the proliferative potential of normal rat mammary epithelial cells in vitro. J. Cell. Physiol., 132:161-167.

Ethier, S.P., Summerfelt, R.M., Cundiff, K.C., and Asch, B.B. (1990) The influence of growth factors on the proliferative potential of normal and primary breast cancer-derived human breast epithelial cells. Breast Cancer Res. Treat., 17:221-230.

Ethier, S.P., Moorthy, R., and Dilts, C.A. (1991) Secretion of an epidermal growth factor-like growth factor by epidermal growth factorindependent rat mammary carcinoma cells. Cell Growth Differ 2:593-602.

Fedi, P., Pierce, J.H., Difiore, P.P., and Kraus, M.H. (1994) Efficient coupling with phosphatidylinositol 3-kinase, but not phospholipase $\mathrm{C}$ gamma or GTPase-activating protein, distinguishes erbB-3 signaling from that of other erbB EGFr family members. Mol. Cell. Biol., 14:492-500.

Hammond, S.L., Ham, R.G., and Stampfer, M.R. (1984) Serum-free growth of human mammary epithelial cells: Rapid clonal growth in defined medium and extended serial passage with pituitary extract. Proc. Natl. Acad. Sci. U.S.A. 81:5435-5439

Holmes, W.E., Sliwkowski, M.X., Akita, R.W., Henzel, W.J.J.L., Park, J.W., Yansura, D., Abadi, N., Raab, H., Lewi, G.D., Shepard, M. Kuang, W.J., Wood, W.I., Goeddel, D.V., and Vandlen, R.L. (1992) Identification of heregulin, a specific activator of p185erbB2. Science, $256: 1205-1210$

Kraus, M.H., Issing, W., Miki, T., Popescu, N.C., and Aaronson, S.A (1989) Isolation and characterization of ERB-B-3, a third member of the ERBB/epidermal growth factor receptor family: Evidence for overexpressionin a subset of human mammary tumors. Proc. Natl. Acad. Sci. U.S.A., 86:9193-9197.

Kraus, M.H., Fedi, P., Starks, V., Muraro, R., and Aaronson, S.A 1993) Demonstration of ligand-dependent signaling by the erbB-3 tyrosine kinase and its constitutive activation in human breast tumor cells. Proc. Natl. Acad. Sci. U.S.A., 90:2900-2904.

Peles, E., Levy, R.B., Ullrich, A., and Yarden, Y. (1991) Oncogenic forms of new/HER-2 tyrosine kinase are permanently coupled to phospholipase C-gamma. EMBO J., 10:2077-2086.

Peles, E., Benlevy, R., Tzahar, E., Liu, N.L., Wen, D.Z., and Yarden, Y. (1993) Cell-type specific interaction of neu differentiation factor
(NDF heregulin) with neu/HER-2 suggests complex ligand receptor relationships, EMBO J., 12:961-971.

Plowman G.D. Whitney, G.S., Neubauer, M.G., Green, J.M., McDonald, V.L., Todaro, G.J., and Shoyab, M. (1990) Molcular cloning and expression of an additional epidermal growth factor receptor-related gene. Proc. Natl. Acad. Sci. U.S.A., 87:4905-4909.

Plowman, G.D., Culouscou, J.M., Whitney, G.S., Green, J.M., Carlton, G.W., Foy, L., Neubauer, M.G., and Shoyab, M. (1993a) Ligandspecific activation of HER4/p180(erbB4), a 4th member of the epidermal growth factor receptor family. Proc. Natl. Acad. Sci. U.S.A., $90: 1746-1750$

Plowman, G.D., Green, J.M., Culouscou, J.M., Carlton, G.W., Rothwell, V.M., and Buckley, S. (1993b) Heregulin induces tyrosine phosphorylation of HER4/P180(erbB4). Nature, 366:473-475.

Ro, J., El-Naggar, A., Ro, J.Y., Blick, M., Frye, D., Fraschini, G., Fritsche, H., and Hortobagyi, G. (1989) c-erbB-2 amplification in node-negatie human breast cancer. Cancer Res., 49:6941-6944.

Slamon, D.J., Clark, G.M., Wong, S.G., Levin, W.J., Ullrich, A., and McGuire, W.L. (1987) Human breast cancer: Correlation of relapse and survival with amplification of the HER-2/neu oncogene. Science, 235:177-182.

Sliwkowski, M.X., Schaefer, G., Akita, R.W., Lofgren, J.A., Fitzpatrick, V.D., Nuijens, A., Fendly, B.M., Cerione, R.A., Vandlen, R.L., and Carraway, K.L. (1994) Coexpression of erbB2 and erbB3 proteins reconstitutes a high affinity receptor for heregulin. J. Biol Chem., 269:14661-14665.

Soule, H.D., Malony, T.M., Wolman, S.R., Peterson, W.D., Brenz, R., McGrath, C.M., Russo, J., Pauley, R.J., Jones, R.F., and Brooks, S.C. (1990) Isolation and characterization of a spontaneously immortalized human breast epithelial cell line, MCF-10. Cancer Res., 50. 6075-6086.

Stampfer, M.R., Hallowes, R.C., and Hackett, A.J. (1980) Growth of normal human mammary epithelial cells in culture. In Vitro, 16:415-425.

Wen, D., Peles, E., Cupples, R., Suggs, S., Bacus, S.S., Luo, Y., Trail, G., Hu, S., Silbiger, S., Levy, R.B., Koski, R., Lu, H.S., and Yarden, Y. (1992) Neu differentiation factor: A transmembrane glycoprotein containing an EGF domain and an immunoglobulin homology unit Cell, 69:559-572.

Zeillinger, R., Kury, F., Czerwenka, K., Kubista, E., Sliutz, G., Knogler, W., Huber, J., Zielinski, C., Reiner, G., Jakesz, R., Staffen, A., Reiner, A., Wrba, F., and Spona, J. (1989) HER-2 amplification, steroid receptors and epidermal growth factor receptor in primary breast cancer. Oncogene, 4:109-114. 